Translating Differences: An Interview with Zineb Sedira

Author(s): Joseph McGonagle and Zineb Sedira

Reviewed work(s):

Source: Signs, Vol. 31, No. 3, New Feminist Theories of Visual Culture (Spring 2006), pp. 617628

Published by: The University of Chicago Press

Stable URL: http://www.jstor.org/stable/10.1086/498990

Accessed: $18 / 01 / 201212: 12$

Your use of the JSTOR archive indicates your acceptance of the Terms \& Conditions of Use, available at http://www.jstor.org/page/info/about/policies/terms.jsp

JSTOR is a not-for-profit service that helps scholars, researchers, and students discover, use, and build upon a wide range of content in a trusted digital archive. We use information technology and tools to increase productivity and facilitate new forms of scholarship. For more information about JSTOR, please contact support@jstor.org. 


$$
\begin{array}{r}
\text { Joseph McGonagle } \\
\text { Zineb Sedira }
\end{array}
$$

\section{Translating Differences: An Interview with Zineb Sedira}

\section{A}

British-based artist, Zineb Sedira was born in Paris to Algerian parents in 1963. Her work, underpinned by this cross-cultural identity, has been highly autobiographical and examines themes such as cultural identity, memory, translation, language, and diaspora. Her art spans film, photography, video, and installation.

Sedira has exhibited widely across Europe, the Middle East, and the United States. Her first major solo exhibition took place from January 10 to February 22, 2004, at the Cornerhouse arts and cultural center in Manchester, UK. A DVD-ROM, Telling Stories with Differences (2004), which features a selection of Sedira's video works, was issued to accompany the exhibition. Images of many of her works can also be consulted on Sedira's own Web site, http://www.zinebsedira.com. The following interview took place in London on February 26, 2004.

Joseph McGonagle (JM): Your work at the exhibition at the Cornerhouse dealt predominantly with the politics of identity, especially that of women, and women have featured heavily in your previous pieces, too. Why have you traditionally chosen to focus on women and their experiences?

Zineb Sedira (ZS): Well, I actually did my BA at Central Saint Martins in London, where I was taught by feminist artists who had practiced since the 1970s. Their practice and ideas really influenced me; hence, I became interested in the 1970s feminist art movement, which condemned the representation and objectification of women in the media and advertising. This was the starting point to my concentration on the subject in general, whatever the women's culture or where they lived. This led me to develop my interests in the way nonwhite, black, or Arab women had been represented through orientalist imagery.

$J M$ : Your work focuses on your mother, and on your daughter as well. Why did you decide to include them?

$Z S$ : Obviously, being a woman myself and working around women's issues, I started looking at myself and the women around me. I also became a mother while I was studying at Central Saint Martins, so I started looking 
at motherhood, investigating my own relationship with my mother. I thought about the way my mother educated us, relating it to myself as a mother. So, the ideas of language, generational transmission, and translation started to interest me: the way we speak, the way we are, the way we think, and even the way we dress. I was fascinated by the fact that in the same family - composed of three generations - there were three countries of birth and three languages. My mother was born in Algeria and speaks Arabic, my daughter was born in England and speaks English, and I was born in France and speak French. The idea of taking photographs of my mother, my daughter, and myself came about because I wanted to represent women within the same family through their body language and clothing. My mother dressed in her traditional Algerian outfit; my daughter in an urban, funky top and trousers; and I wore a pseudo-Eastern tunic, which is so fashionable in Europe. I was obviously the in-between or the mediator linking my mother and daughter. So, because I felt I had a family with an interesting narrative, understandably I used them to illustrate issues around cultural identity and gender.

$J M$ : Perhaps it's like what they say about writers: you shouldn't write about what you don't know; you should only write about your own life story.

$Z S$ : Initially art was for me, in some ways, therapeutic. Art helped me to exorcise emotions and ideas. I was only able to express myself through art while away from France.

$J M$ : So was it a conscious decision to move to England then?

$Z S$ : No, I didn't move to England because of art. I was eighteen and wanted to visit London-learn English while partying. In France, at the time, London was seen as the happening place. Later, when I went to art college, I studied for a BA in critical fine art practice, where postcolonial studies was an important component of the course's cultural studies element. Consequently, this program inspired my art practice.

$J M$ : Do you think you would be doing the same work if you had stayed in France? It sounds as if your decision to leave France has proved integral to your development as an artist.

$Z S$ : At the time, in France, it was not really possible for a FrancoAlgerian to study in art colleges. Engaging in postcolonial ideas was not an option. I would like to think-had I studied in France-that my work would be framed by my Algerian identity. Who knows, the work could have been even more political. I'm pleased I studied in London, where I learned about postcolonial issues. It's still not part of French art education. It is here that I discovered people like Frantz Fanon and the French- 
Algerian writers Jacques Derrida and Hélène Cixous. I knew of Albert Camus; however, French schools do not label him as Franco-Algerian.

$J M$ : Since we've touched on family and Algerianism, two of your works that particularly struck me were Retelling Histories (2003) and Mother, Father and I (2003), where your parents speak in great detail about their own lives and experiences. Why did you choose to film them, rather than strangers?

ZS: Those pieces were made after the Mother Tongues piece (2002), so there was this element of language and documentary I was interested in. At the time, there was much discussion in the French media about the Algerian war and particularly about October 17, 1961 [a notorious massacre in Paris by French police of up to 250 Algerian civilians who were protesting peacefully against a police curfew imposed on Algerians in Paris]. For the first time, France had agreed to put a commemorative plaque on one of the bridges in Paris where hundreds of Algerians were drowned. This led to a dispute over whether the French government should even acknowledge the massacre. I was really disappointed. It was only a small plaque, and I felt this was the least they could do. Added to that, I knew my dad had also participated in that peaceful October 1961 march, so I decided to ask him some questions about his involvement. For the first time, my father spoke about his full participation in the march, and I decided to record it. My parents were also more implicated than I had thought in the Franco-Algerian war. For example, I discovered that both my father and mother had been freedom fighters. I went back to France and began filming their stories. I wanted to do a serious piece about their contribution to the war. I didn't really know how I would present the final piece of work, but I felt an urge to listen. Equally, my parents expressed their wish to talk about it. I also wanted to circulate the interview film among my brothers and sisters because none of them knew how much my parents had suffered during colonial times. Later, my father was really proud of the film and showed the recording to other members of the family. There were a lot of tears and painful memories that resurfaced. It was very important not to lose the spontaneity of the interview so I deliberately recorded them only once. Out of the three hours of footage, the final version was edited down to twenty minutes for each of my parents. When editing, I realized the way the questions had been asked weren't how I would have wished. I decided to remove the sound of my voice and instead include myself listening visually to my parents. The final piece is a three-screen video installation and is titled Mother, Father and I (fig. 1). It works well as a triangle and continues my fixation with triptychs. 


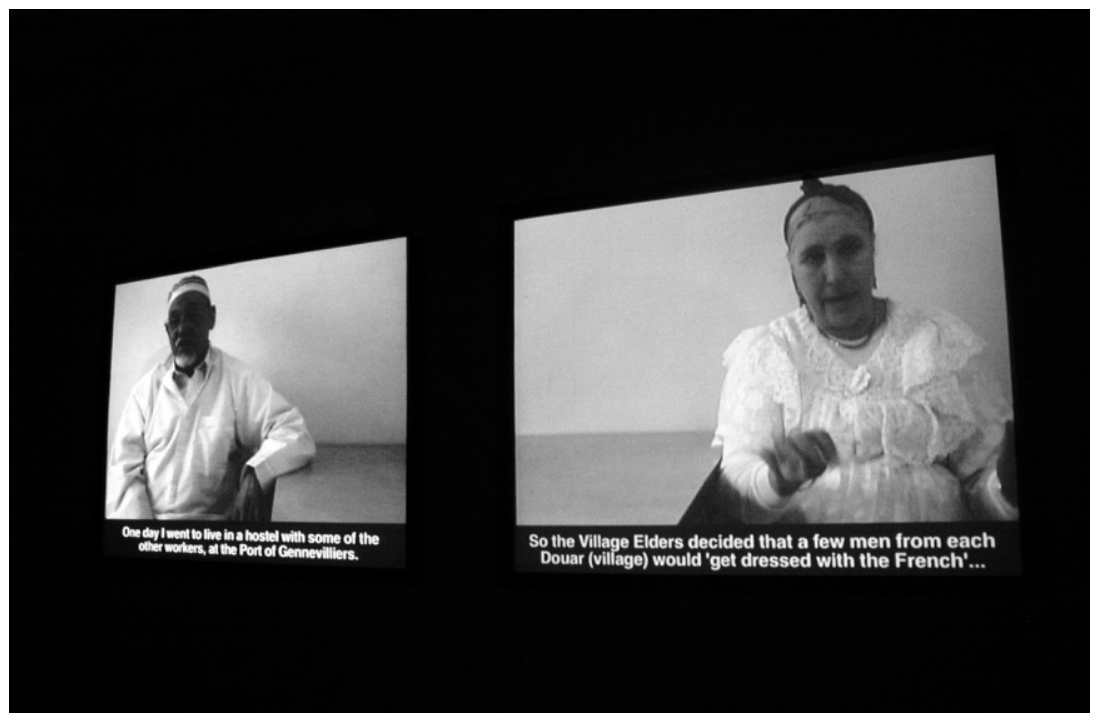

Figure 1 Zineb Sedira, Mother, Father and I (2003). Color version available as an online enhancement.

$J M$ : Did you actually film yourself listening to these stories?

$Z S$ : Yes. In fact, I filmed myself watching the video. I wanted to record my reactions to my parents' narratives. I'm very pleased with the final version. Although I've moved on now from this type of work, I think it's a successful piece. Retelling Histories happened at the same time as Mother, Father and I; however, Retelling Histories presents the Algerian war from a woman's position. The languages and interview format used in the video strengthen the work. I ask questions using the colonizer's language, French, and my mother answers in the colonized's indigenous language, the Algerian dialect. Both languages are also heard in Mother, Father and I. There my father converses in a mixture of French and Algerian, while my mother speaks her native tongue throughout, as she was a housewife in France and remained less exposed to French than my father, who worked outside the home. Again, in Mother, Father and I the two languages, French and Arabic, work well together.

$J M$ : When your films and videos are projected in exhibitions, do you specify size of screen, and so forth?

$Z S$ : Yes, I do. At the Cornerhouse, it was the first time Mother, Father and $I$ was shown in such large scale. Usually the piece is exhibited in a much smaller, more intimate space. The Cornerhouse's top gallery was in fact too large.

$J M$ : Examples of testimony recur throughout your work. I recently 
read a review in the Guardian newspaper by a reviewer who praised your work but felt that it was more testimony than art itself (Hickling 2004). How would you respond?

$Z S$ : Many video artists make testimonial work, although it's often seen as documentary art video. The question often asked is whether the work can be considered contemporary art. Is political work art? Or should politics only be referred to in TV news, documentaries, or newspapers? Many of these documentary art films are produced by artists from countries that are at war or that are undergoing significant political struggle. The work-although mimicking conventional documentary style-reinforces these issues in a more poetic and philosophical way. To return to your comment, yes, my work is testimonial, and it should be accepted as art.

$J M$ : How important is it that when you film such pieces you are being told these stories for the very first time? What does that bring to a piece?

$Z S$ : Well, for me it brings spontaneity, naturalness, and greater facts, as well as honesty. I make the conscious decision to keep any recorded mistakes. Perhaps this is the difference between TV documentary and art: I am not looking for perfection. This is particularly noticeable in the video piece Retelling Histories: the sound is of low quality in comparison with Mother, Father and I, where the sound was recorded professionally. Such imperfection springs from my limited technical knowledge, which then sometimes becomes part of the work itself-for instance, doing work in my parents' kitchen, only using existing lighting, and filming just with my modest camera. I see my videos as a kind of home movie.

$J M$ : Since you use different types of media, I wondered how conscious your choice between them was. What makes you choose photography rather than create an installation?

$Z S$ : I don't know really. Sometimes it's determined by commissions. For example, in St. Louis, the curator wanted to commission a new video and photography piece. We agreed on what would become the video Mother, Father and I and the photography piece Mother, Daughter and I (2003). The video installation On a Winter's Night, a Traveller (2003) was also a video commission by the Museum of African Art in New York. Occasionally, it's the commission that determines the medium of the work; at other times, I am free to choose.

$J M$ : What, in your opinion, are the qualities of each medium?

$Z S$ : Well, for me, video is enjoyable, as I've got my own camera. It allows me to film spontaneously almost whenever I want. In some ways with video I have more control. In the past, I always had to work with professional editors, relying on their expertise. Now I have learned the 
basics of editing, so it gives me some freedom. However, depending on the scale of the work and the complexity of the editing, I still have to work with an editor. Photography? I'm not a photographer per se, in terms of being technically skilled. I can use a $35 \mathrm{~mm}$, but beyond that I'm kind of useless. So, when using studio photography, I work with a professional studio photographer. He does all the lighting and camera settings for me. The medium of photography is more challenging, as it requires greater organization, but I still like working with it. As demanding as it is, it makes sense to work within a studio setting, as I've always liked studio portraiture.

$J M$ : At the opening of your exhibition at the Cornerhouse in Manchester, you said that you felt your work was moving from an interest in people to an increasing interest in landscapes. Could you elaborate further?

$Z S$ : Well that's the advantage of my video camera. I can just hold it and film. When I am in Algeria I mainly film land- and cityscapes because it's a country where it is difficult to film individuals. I am also attracted by these settings as I travel a great deal while in Algeria, using various means of transport-first of all at the airport or port, where I take the plane or ferry, then by car or taxis when traveling inland. You see, my parents don't live in Algiers, so to visit them, I rely largely on taxis. The taxi journey through the Kabylia Mountains contains some stunning scenery. I just film continuously while in the car until I arrive. I guess this appetite or curiosity for the Algerian landscape came from rediscovering Algeria after twelve years of exile. I forgot how beautiful my parents' home was. On a Winter's Night, a Traveller was born at that time, just on the spur of the moment.

$J M$ : Do you plan to continue in this vein?

$Z S$ : Yes. I've also got some footage of seafronts taken while I was traveling by car. I will use it at some point. Currently I'm planning an important film production planned for 2006-7. It will be a three-screen installation about me traveling back to Algeria. Most of it will be set on the ferry from Marseilles to Algiers to Marseilles. It has often been said that the two cities, Marseilles and Algiers, mirror each other. They are both situated by the Mediterranean Sea and located on a mountain, each with a cathedral overlooking the bay. It's also an important historical trip. When the Algerians won the war of independence in 1962, the French army and settlers living in Algeria had to leave. They traveled from Algiers to Marseilles by ferry. It is a well-known journey among Algerian immigrants. My father made this trip on many occasions. So, as I was saying, the production will be considerable as I will be accompanied by a film 
crew. I would like the film to be poetic and mainly landscape based, hopefully with a spoken narrative written by me.

$J M$ : Lots of your work-for example, La maison de ma mère (Algeria) (2002; My mother's house) - contains shots of homes and interior spaces, of privacy and intimacy. Why have you often filmed and photographed inside rather than outside?

$Z S$ : Well, La maison de ma mère was a commission-for the exhibition Fold - by the City of Leicester Gallery. As the title suggests, the exhibition was looking at folds in draperies and cloths. I had two months to create it, but as I was going on holiday to Algeria, I could only do the work while I was away. When I arrived at my mother's house, I realized it would be the perfect setting for the photography piece. The house was full of folds, draperies, curtains, and so forth. . . . I photographed the interior of the house, creating a kind of kaleidoscope, a mosaic representing fragments of curtains, bedsheets, pillows, table covers, my mother's dress, and so on. It's a small and simple piece, but I think it works well.

$J M$ : So it's a practical consideration as much as anything else.

$Z S$ : Yes, it can be.

$J M$ : Because I noticed in your work that the interviews with your parents appear to have been shot in a kitchen.

$Z S$ : Yes, it's in my parents' kitchen in Paris. I didn't do the interviews in Algeria as my parents come back to Paris every year for a few months. So, I filmed them in Paris as I was there. I like working with what I've got around me and don't really like planning in advance. I like being independent and spontaneous. In the same way, I have created works at my mother's house in Algeria without any prior planning. I often work in this manner, that is, if I'm fortunate enough to have my video or photographic camera with me. I believe that a family photograph can become an artwork if it illustrates some of the issues I am working on.

$J M$ : Since we're talking about Algeria, it's fascinating to consider two of the works on exhibition, Silent Sight (2000) and From the Series SelfPortraits, Self-Portrait or the Virgin Mary (2000), given what's happening in France at the moment regarding the recent (February 2004) bill passed outlawing religious symbols in French schools. Do you express a view on what's happening in France?

$Z S$ : Yes, of course I have a view. I have family in France, sisters and sisters-in-law who wear the headscarf. As expected, they are alarmed about the ban of the hijab in schools as it goes against their religious practice not to wear it. I think you have to understand the history of secularism within France. Historically, the state has forbidden religion in schools and 


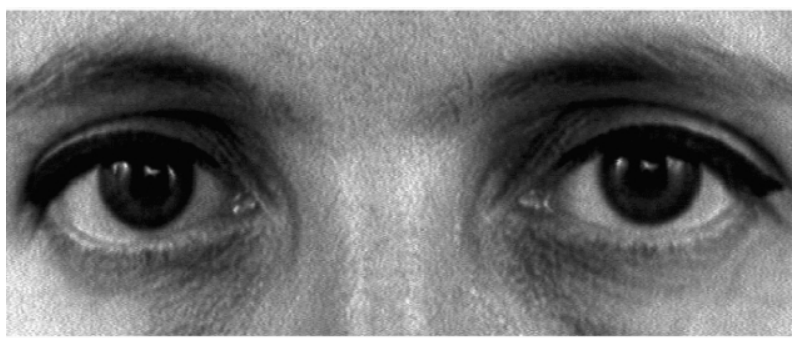

Figure 2 Zineb Sedira, Silent Sight (2000)

government establishments. However, I think it is now time for French society to change their laws on religion and education and adapt their policies to an increasingly multicultural society.

$J M$ : How do you feel looking back now at these two pieces, Silent Sight and From the Series Self-Portraits, Self-Portrait or the Virgin Mary? Do you feel you achieved the aims you set [for] yourself?

$Z S$ : Yes, I think I did. Silent Sight (fig. 2) was basically a video piece about my mum wearing the haik - the Algerian veil-when she traveled to Algeria. I wanted the video to voice a child's feelings about seeing her mother disappear under a veil. The veil has always been vigorously discussed by adults: Is the veil a good or bad thing? So I put into writing my recollections of traveling to Algeria-when I was eight or nine-with my mother. She used to wear her veil over her Western attire on arrival at Algiers airport. I speak about my worries seeing her change into a "local" woman. As the story unravels, I end the text with "it's my home, her home, and I just accepted it." What I am trying to say is that the veil, for me, is part of my parents' tradition.

Regarding Self-Portrait or the Virgin Mary (fig. 3), my aims were not so dissimilar. Both it and Silent Sight were created around the same time. They were both a reaction to the media polemic surrounding veiling. The veil shown in the media is always black and a chador, ignoring the variety of shapes, forms, and colors of veils. I wanted to show the Algerian white veil by using it in the photographs. The work is in some ways simplistic, but it's done with a pinch of irony. I just wanted to remind those in the West that veiling also existed in Christianity and that the Virgin Mary is an example of it. Moreover, people forget that nuns, still today, wear a veil. Yes, I do still feel strongly about the ideas behind the work.

What I find interesting is that some people when looking at the workespecially the Self-Portrait or the Virgin Mary-find the images beautiful. Yet others see the veil in the work as oppressive and sexist. I think there is nothing sexist or oppressive about it. The work is actually very fresh 


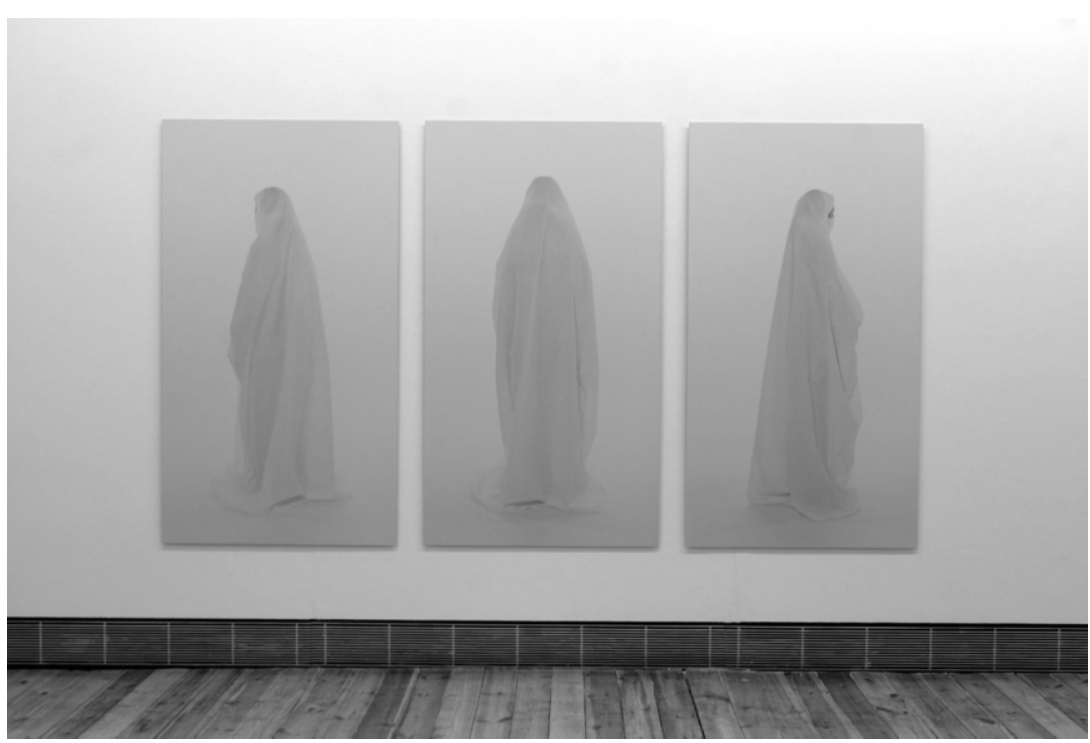

Figure 3 Zineb Sedira, Self-Portrait or the Virgin Mary (2000). Color version available as an online enhancement.

and light and has a meditative sensitivity about it. It overturns Western stereotypes about the veil. My views haven't changed about the Silent Sight and Self-Portrait or the Virgin Mary pieces. However, I do not want to do work about veiling anymore. I have moved on.

$J M$ : So how do you feel personally about being labeled as an artist who deals specifically with the veil? Do you feel pigeonholed?

$Z S$ : Yes, I have been pigeonholed, but I'm now starting to get out of it. What I found interesting about the solo show at the Cornerhouse was that Kathy Rae Huffman [director of visual arts] didn't invite me to exhibit because of my pieces about the veil. At the Venice Biennale, she had seen one of my earlier pieces, which had nothing to do with veiling. But when I actually came to work with the press officer, again I was asked to mention the veil works. However, Kathy and I agreed that I would work closely with her on the exhibition and press release so that they represented my whole body of work. I had to be very assertive. As an artist, you have to be very firm, especially when you do work such as mine. Curators and art critics can sometimes be lazy. It is easier to label than to understand certain works, especially when they deal with unfamiliar issues. It's a real battle; however, I'm becoming happier with the way my work is now interpreted.

$J M$ : Maybe the fact that you're moving toward filming landscapes and journeys will help; it'll be harder to position you as easily. 
ZS: Well, many black artists-including myself-have argued that as long as their art work includes black signifiers, whether in terms of object or person, the work will be labeled as black art. Consequently, these artists feel they can't be part of the mainstream art scene. But let's not generalize; we know that some of these artists—albeit a small minority — are also doing very well. Yes, it is true that with my move away from more obvious autobiographical aspects such as family to filming landscapes and travel (even though situated in Algeria), audiences might read my work as more universal. I hope so anyway.

$J M$ : Your work has also been exhibited in France. Did you sense a difference in reaction to how your work has been received here in the United Kingdom?

ZS: Most certainly. For example, Retelling Histories is now in Paris. The show opened last November. The curator had invited the artists for a talk there, so I went. The exhibition was called Voyages d'artistes, and it brought together ten Algerian and non-Algerian artists. Many French people were in the audience, and when I began talking about the piece, they started to mention their own relationship with the Algerian war of independence. Some of them had experienced it, but most had a parent who had fought during the war. Some of them were born in Algeria prior to independence and had to leave the country when the war finished. They spoke about the trauma of leaving. Many were in the army at that time and talked about how terrible this particular war was. So there was a direct relationship with the issues raised in the video piece. This could not have happened in England. The work was more influential in France, and people reacted very strongly to it. I am looking forward to when the other piece, Mother, Father and I, is exhibited there too, because it narrates the Algerian war and subsequent immigration in an even more effective way. It will form part of a show at the Centre Pompidou in Paris in May 2005 , where I knew that the video installation would be just right. It had to be seen in a venue there as prestigious as the Centre Pompidou. There is bound to be a significant audience.

$J M$ : In what state do you think Franco-Algerian relations are at the moment? It sounds from what you're saying that you think France is still largely in denial.

$Z S$ : Over the last five years the press has conveyed some of the experiences of French people during the Algerian war. Recent accounts have been about the denunciation of the practice of torture on Algerian civilians. Unfortunately, living in England, I am not able to keep an eye on what is said or printed. However, when I go back I rummage around for interesting information on the subject. Regarding awareness among the 
general French public, except for the ones who went to war, I don't think they realize how bad it was.

$J M$ : There's still a lot of silence around it.

$Z S$ : Yes, there is still a lot of silence around French involvement in Algeria. I think the French prefer to concentrate on what they see as their main concern: the integration of the children of immigrants in inner cities. I'm sure the average French person doesn't really understand why or how these children happen to be there. It's the French legacy of colonization and war.

$J M$ : So could you explain further how different members of your audience in France reacted to your work?

$Z S$ : When I exhibited in Voyage d'artistes, I realized that the way Algerians living in Algeria reacted to Retelling Histories was very different from the way Franco-Algerians did. In some ways they were more blasé about the issue of the Algerian war because they had grown up hearing many stories like my parents'. I also noticed that the Algerian war or colonization is often explored (via writing or art) by the children of Algerians living in France. This makes sense in some way, as these children did not grow up with Algerian memoirs of the war. Upon researching their origins, they found a version that was very different from the one told by French historians. Hence, their interest in the issue has to do with their parents' experience of colonization.

$J M$ : It's interesting that you say that when, in Yamina Benguigui's documentary Mémoires d'immigrés (1997) and, say, the films of the midnineties by Malik Chibane, it's the first generation who are silenced and the second generation that makes them speak.

$Z S$ : If you look at beur literature [the word beur derives from French back slang and is used to refer to the children, born in France, of North African immigrants] many Franco-Algerian writers like Azouz Begag wrote about Algerian immigration and the war via their parents' experiences. Begag sometimes does so humorously, and I think his writing is compelling. I guess the first generation didn't want to speak about their experiences as they were still fresh and therefore too painful.

$J M$ : You mention the word beur, which has proved a controversial term in France. What do you think about its use?

$Z S$ : Well I don't like it personally, but I use it usually out of laziness. It's easier than saying "Franco-Algerian" or "children of Algerian immigrants" or again "second generation." But yes, it's controversial in the sense that no one wants to be labeled. In verlan [French back slang] arabe becomes rebeu, which is reversed once more to beur. The word beur sounds like the word for butter in French [beurre], and that's one reason why 
people don't like it, as it implies they are merely butter on the French baguette. No one likes to be labeled in a pejorative way.

$J M$ : But it's so commonplace in France.

$Z S:$ My generation tends to use it.

$J M$ : Do they have an alternative name now? Is it no longer an issue?

$Z S$ : I don't really know, and that's a good question. When I go back to France, I'll check with my nieces and see if they are still called beurs or beurettes, or called Franco-Algerian or French, or some other designation.

Department of Modern Languages

University of Wales, Bangor (McGonagle)

London (Sedira)

\section{References}

From the Series Self-Portraits, Self-Portrait or the Virgin Mary. 2000. Photography by Zineb Sedira.

Hickling, Alfred. 2004. "Zineb Sedira." Guardian, January 19, 20.

La maison de ma mère (Algeria). 2002. Photography by Zineb Sedira.

Mémoires d'immigrés. 1997. Film. Directed by Yamina Benguigui. Paris: Canal+. Mother, Danghter and I. 2003. Photography by Zineb Sedira.

Mother, Father and I. 2003. Directed by Zineb Sedira. Video installation. Independently produced.

Mother Tongues. 2002. Directed by Zineb Sedira. Video installation. Independently produced.

On a Winter's Night, a Traveller. 2003. Directed by Zineb Sedira. Video installation. Independently produced.

Retelling Histories. 2003. Directed by Zineb Sedira. Video. Independently produced. Silent Sight. 2000. Directed by Zineb Sedira. Film. Independently produced.

Telling Stories with Differences. 2004. By Zineb Sedira. DVD-ROM. Manchester: Cornerhouse. 